\title{
Effect of Compatibilizer Content on the Tensile Properties and Fracture Toughness of High Density Polyethylene/Polystyrene Blends
}

\author{
Shi Ai Xu ${ }^{*}$ and Sie Chin TJong ${ }^{* *+}$ \\ ${ }^{*}$ Institute of Polymer Science and Engineering, East China University of Science and Technology, \\ 130 Mei-Long Road, Shanghai 200237, People's Republic of China \\ ** Department of Physics and Materials Science, City University of Hong Kong, \\ 83 Tat Chee Avenue, Kowloon, Hong Kong
}

(Received July 5, 1999)

\begin{abstract}
High-density polyethylene (HDPE)/polystyrene (PS) blends were compatibilized with a (styreneethylene/butylene-styrene) tri-block copolymer (SEBS). Both uncompatibilized and compatibilized HDPE/PS 80/20 blend specimens were prepared in a twin-screw extruder followed by injection molding. The effect of SEBS content on the tensile properties of the blends was investigated. It was found that the modulus and yield stress of the HDPE/PS $80 / 20$ blend tend to decrease with increasing SEBS content. However, the elongation at break of the blend improved significantly with the addition of SEBS, indicating the effectiveness of compatibilizing effect of a tri-block copolymer in the immiscible HDPE/PS system. Scanning electron microscopy examination showed that PS phase is fibrillated in the matrix as long fibers, and the SEBS copolymer addition appears to reduce the domain size of PS phase effectively. The fracture toughness of the blends was evaluated by the essential work concept. The result showed that the essential work of the compatibilized HDPE/PS blends also increases with increasing SEBS content.
\end{abstract}

KEY WORDS Polystyrene/Polyethylene/Compatibilization/Fracture Toughness / Essential Work/

Polymer blending is generally known to be an effective route to obtain new and tailor-made materials with specific desirable properties. However, most polymer pairs are immiscible, and they usually exhibit a weak interfacial adhesion and poor mechanical property. To improve the interfacial bonding of the immiscible polymer blends, it is necessary to incorporate the compatibilizers into the blends. The compatibilizers are normally block or graft copolymers, often containing segments chemically identical to the component polymers of the blend, but can also be functionalized polymers containing reactive side groups. The compatibilizers act as emulsifiers, thereby reducing the interfacial tension between immiscible polymers in the melt during blending, leading to a finer dispersion of one phase in another.

Polyethylene (PE) and polystyrene (PS) are the most widely used plastics. PS is a typical glassy polymer that exhibits high strength, high modulus, and excellent dimensional stability, but poor ductility. On the contrary, PE shows high toughness and good impact performance even at low-temperature. However, the high-density polyethylene (HDPE)/PS blends exhibit low interfacial adhesion between the polymer components, leading to inferior mechanical properties. ${ }^{1-3}$ Compatibilization of $\mathrm{PE}$ and PS blends has been the subject of considerable research interest and development effort. ${ }^{1,4-22}$ For example, Paul and coworkers, ${ }^{1,13}$ and Barentsen and Heikens. ${ }^{12}$ have studied the compatibilizing effects of PE- $g$ PS graft copolymer on the microstructure and mechanical properties of PS/PE blends. Their results showed that the blends modified by the graft copolymers exhibit a higher mechanical strength, but have a low elongation at break. Fayt et al. ${ }^{14-16}$ have systematically studied the effects of the structure, molecular weight and content of

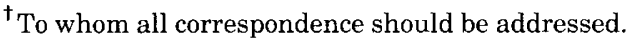

hydrogenated butadiene-styrene diblock copolymer (HPB-b-PS) on the emulsifying efficiency of the PE/PS system. Scanning electron microscopy (SEM) observations revealed that HPB- $b$-PS copolymer triggers a finer and more homogenous dispersion of PE in PS-rich blends or PS in PE-rich blends. ${ }^{15}$ Moreover, the block copolymer tends to locate at the PS/PE interface, and it encapsulates the dispersed particles of either PS or PE. ${ }^{14}$ The mechanical properties of the PS/PE blends compatibilized by the di-block copolymers are greatly improved when compared to those compatibilized by the graft copolymers. More recently, Taha and Frerejean ${ }^{23}$ have compatibilized the PS/low density PE blends using commercially available hydrogenated butadiene-styrene (SEB) copolymer, and polystyrene-hydrogenated polybutadiene-polystyrene (SEBS) tri-block copolymers. They reported that both finer and more stable dispersion in PE/PS blends could be achieved with the incorporation of a diblock copolymer. Similarly, Li et al. also reported that both SEB and SEBS block copolymers are very effective in reducing the domain size of PS. ${ }^{20}$

In a previous paper, ${ }^{11}$ we have studied the tensile and impact properties of HDPE/PS blends compatibilized with SEBS. Tensile measurements showed that the elongation at break of HDPE/PS blends tend to increase dramatically with increasing HDPE content. Charpy impact measurements indicated that the impact strength of the blends increases slowly with HDPE content up to $50 \mathrm{wt} \%$, followed by a significant increase with further increasing the HDPE content. Moreover, the elongation at break and the impact strength of some HDPE-rich blends exceed those of pure HDPE polymer. This means that HDPE can be further toughened by brittle PS minor phase in the presence of SEBS compatibilizer. It is noted that a high amount of SEBS (10 wt\%) was added in the HDPE/PS blends. It is considered that some SEBS age- 
nts act as emulsifiers, whereas others tend to disperse in $\mathrm{PE}$ the phase, acting as a rubber toughening agent.

The effects of the addition of SEBS tri-block copolymer on the morphology and static tensile behavior of PS/PE blends have been extensively investigated by several researchers. ${ }^{11,17,20-26}$ However, little information is available about the effects of SEBS content on the morphology and mechanical properties of HDPE/PS blends, especially the effect of SEBS copolymers on the fracture toughness of the PE/PS blends. In this study, we have prepared HDPE/PS 80/20 blends compatibilized by different amounts of SEBS, and studied the effect of SEBS content on the tensile properties and morphology of HDPE/PS 80/20 blends. Moreover, we attempt to use the essential work of fracture concept to determine the fracture toughness of the HDPE/PS blends, and to explore the effects of the SEBS content on the fracture toughness of HDPE/PS 80/20 blends. The essential work method was originally developed by Broberg ${ }^{27}$ for determining the fracture toughness of metallic sheets under plane stress conditions. More recently, many researchers have used this approach to determine the fracture toughness of ductile polymers. ${ }^{28-30}$

\section{EXPERIMENTAL}

\section{Materials}

The homopolymers used in this investigation were commercial grades of PS (Styron 667, Dow Chemical Company) and high density polyethylene (Mobil, blow film B5429, Saudi Arabia). The tri-block copolymer SEBS (G1652) was kindly supplied by Shell company with the respective molecular weights of PS block and central EB block being 7500 and 37500 , and the PS weight fraction being $28.6 \%$.

\section{Blending Conditions}

All materials used were dried overnight separately in ovens, at $80^{\circ} \mathrm{C}$ for PS and HDPE, and at $60^{\circ} \mathrm{C}$ for SEBS. The HDPE/PS $80 / 20$ blend compatibilized with 2-10 wt $\%$ SEBS were prepared by mixing the well-dried pellets in a twin-screw extruder (Brabender Plasticorder), operating at $190-200^{\circ} \mathrm{C}$. The extrudates were pelletized and then dried at $100^{\circ} \mathrm{C}$ for $12 \mathrm{~h}$. Using these pellets, dogbone-shaped tensile bars (ASTM D638), and plaques with dimensions of $200 \times 80 \times 3.2 \mathrm{~mm}$ were injection molded. The barrel zone temperatures were set at 200 , 210 , and $220^{\circ} \mathrm{C}$. Uncompatibilized HDPE/PS $80 / 20$ blend was also prepared under similar processing conditions.

\section{Tensile Test}

The tensile behavior of the blends was determined at $21^{\circ} \mathrm{C}$ with an Instron tensile tester (model 4206) under a crosshead speed of $20 \mathrm{~mm} \mathrm{~min}^{-1}$. The relative humidity during the tests was $65 \%$. A longitudinal extensometer with a gauge length of $50 \mathrm{~mm}$ was employed. Ten specimens of each composition were tested and the average values were reported. The fracture energy of the samples was obtained by integrating the area under the stress-strain curve.

\section{Morphological Observation}

Samples with about $1 \mathrm{~cm}$ length were cut from the middle part of the tensile bars, and dipped in liquid nitrogen for about $30 \mathrm{~min}$. The samples were subsequently fractured along the injection direction. The cryogenically fractured surfaces were then etched in a tetrahydrofuran (THF) solvent for $6 \mathrm{~h}$. Finally, the morphology of the fracture surface was observed in a scanning electron microscope (Jeol JSM 820) after being coated with a thin layer of gold.

\section{Fracture Toughness Test}

The tests were conducted at room temperature $\left(22^{\circ} \mathrm{C}\right)$ using an Instron tensile tester (model 4206). Single edge notched tensile specimens (SENT) with dimensions of $200 \times 25 \times 3.2 \mathrm{~mm}$ were used. They were cut from the injection molded plaques with the longitudinal direction of the specimens parallel to the melt flow direction. The notches were prepared by first forming saw cut slots, which were then sharpened with a razor blade. The razor blade was mounted on a laboratory attachment so that penetration could be controlled carefully. The fresh edge of a razor was then pushed through the material slowly to a depth of about $1 \mathrm{~mm}$. The exact ligament length $(L)$ was measured by a travelling microscope (Topcon Profile Projector). The load applied during extension was monitored with a load cell of an Instron tensile tester. The tensile rate used was $1 \mathrm{~mm} \mathrm{~min}^{-1}$, and the gauge length of samples was $100 \mathrm{~mm}$.

\section{RESULTS AND DISCUSSION}

\section{Morphology}

Figures $1 \mathrm{a}-1 \mathrm{f}$ are the SEM micrographs showing the cryofracture surfaces of HDPE/PS 80/20 blends containing different amounts of SEBS. As the PS phase is extracted by THF, hence only remaining HDPE is observed in these micrographs. It is obvious that PS is dispersed in the HDPE matrix as long fibers for all HDPE/PS blend specimens investigated. This implies that PS phase is fibrillated and oriented along the flow direction during injection molding. The average diameter of PS fibers in the uncompatibilized blend (Figure 1a) is obviously larger than that of the compatibilized blends (Figures $1 \mathrm{~b}-1 \mathrm{f}$ ). Furthermore, the average diameter of the dispersed fibers appears to decrease with increasing SEBS content. In addition, the morphology of the blends show little change when the SEBS content exceeds $6 \mathrm{wt} \%$.

\section{Tensile Mechanical Properties}

Figure 2 shows the stress-strain curves of the pure PS, HDPE, and HDPE/PS 80/20 blend compatibilized by different amounts of SEBS. Apparently, PS is a hard and brittle polymer, which exhibits an ultimate elongation of less than $4 \%$. Its modulus and fracture stress are 3.2 $\mathrm{GPa}$, and $42 \mathrm{MPa}$ respectively. On the contrary, pure HDPE is a typical ductile polymer, which can undergo extensive plastic deformation with a strain up to about $300 \%$ before breaking. However, uncompatibilized HDP E/PS 80/20 blend shows an obviously lower ultimate elongation compared to HDPE, i.e., $\sim 77 \%$ (Curve 2 of Figure 2). Moreover, its modulus and fracture stress are smaller than those of PS. ${ }^{12,13,31}$ This is because the uncompatibilized PS/PE blends inherit poor properties of 

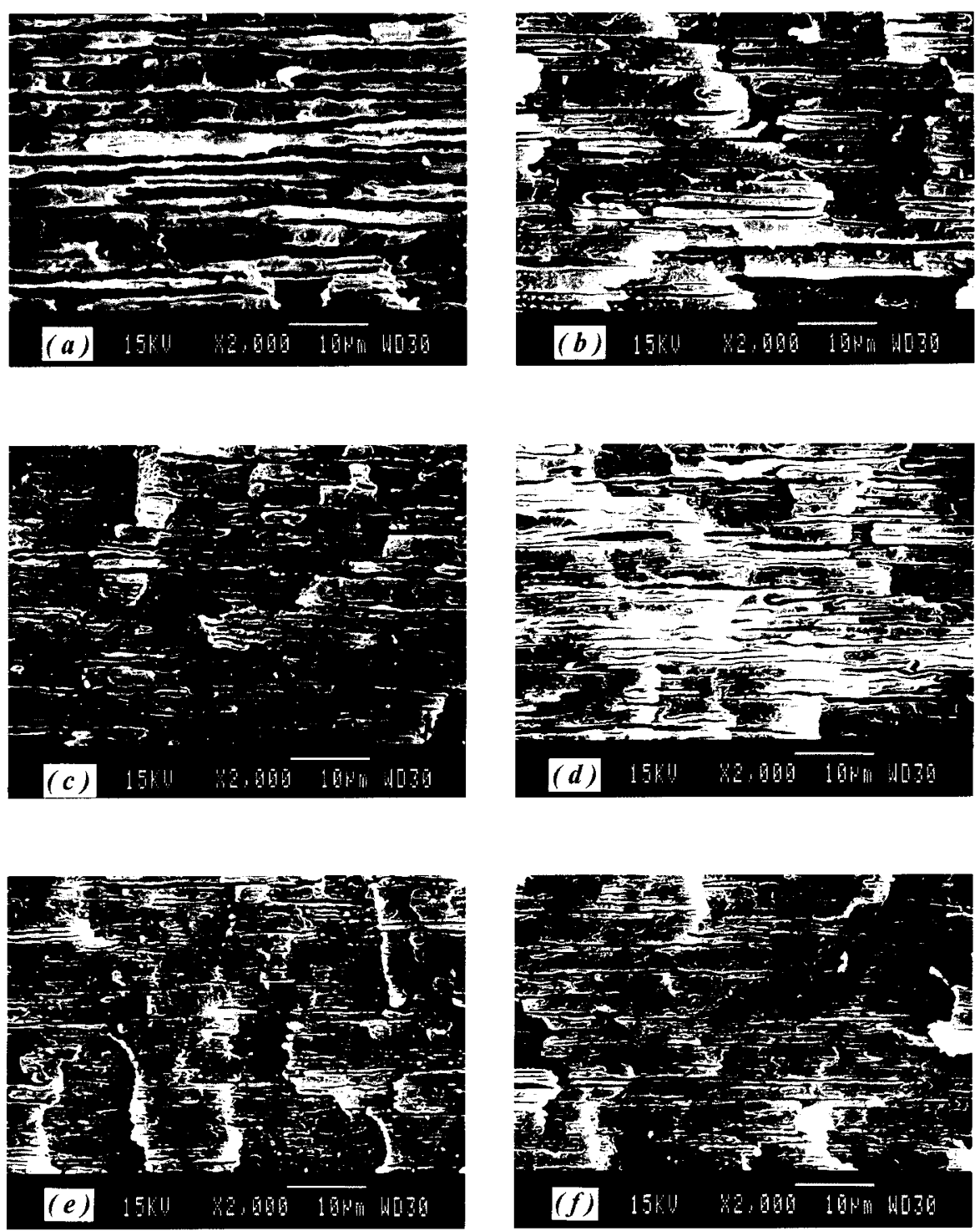

Figure 1. SEM micrographs showing the cryofracture surfaces of HDPE/PS 80/20 blends containing different amounts of SEBS. (a) no SEBS ; (b) $2 \mathrm{wt} \%$ SEBS ; (c) 4 wt\% SEBS ; (d) 6 wt\% SEBS ; (e) 8 wt $\%$ SEBS ; (f) $10 \mathrm{wt} \%$ SEBS (The PS phase is extracted by THF, and the remaining phase is HDPE).

their parent components. From Figure 1, the tensile ductility of HDPE/PS $80 / 20$ blend improves greatly by adding only $2 \mathrm{wt} \%$ SEBS. The tensile strain of HDPE/PS 80/ 20 blend approaches to that of pure HDPE with the incorporation of $6 \mathrm{wt} \%$ SEBS. As the SEBS content increases to $8 \mathrm{wt} \%$, the elongation at break of the blend exceeds that of pure HDPE. It is worth-noting that the tensile behavior of the compatibilized blends is characterized by the presence of yield point and necking followed by a homogenous drawing.

Figure 3 shows the plot of Young's modulus of the blends versus SEBS content for HDPE/PS blend specimens. It can be seen that the modulus of the specimens decreases slowly with SEBS content up to $4 \mathrm{wt} \%$, thereafter, it decreases sharply with increasing HDPE content. When the SEBS content exceeds $6 \mathrm{wt} \%$, the modulus of the blends only varies slightly with increasing SEBS content, and it is close to that of pure HDPE (1.2 $\mathrm{GPa}$ ). Figure 4 shows the elongation at break versus
SEBS content for the HDPE/PS blend specimens. It is apparent that the elongation at break of the blends tends to increase with increasing the SEBS content. It is noted that the elongation at break of the blends having SEBS content $>6 \mathrm{wt} \%$ exceeds that of pure HDPE. A similar behavior is also observed in the plot of fracture energy versus SEBS content (Figure 5). Figure 6 shows the variation of the yield strength of HDPE/PS blends as a function of SEBS content. The yield stress of the blends generally decreases with increasing the SEBS content within the studied range of SEBS content. A sharp decrease in yield stress is observed when the SEBS content $\geq 4 \mathrm{wt} \%$. The yield stress of all blends is higher than that of pure HDPE (24 MPa).

As mentioned above, uncompatibilized HDPE/PS blend generally exhibits poor mechanical properties. Fayt et al. reported that the curves of both tensile strength and ductility against blend composition show a minimum point value which is smaller than those of their 


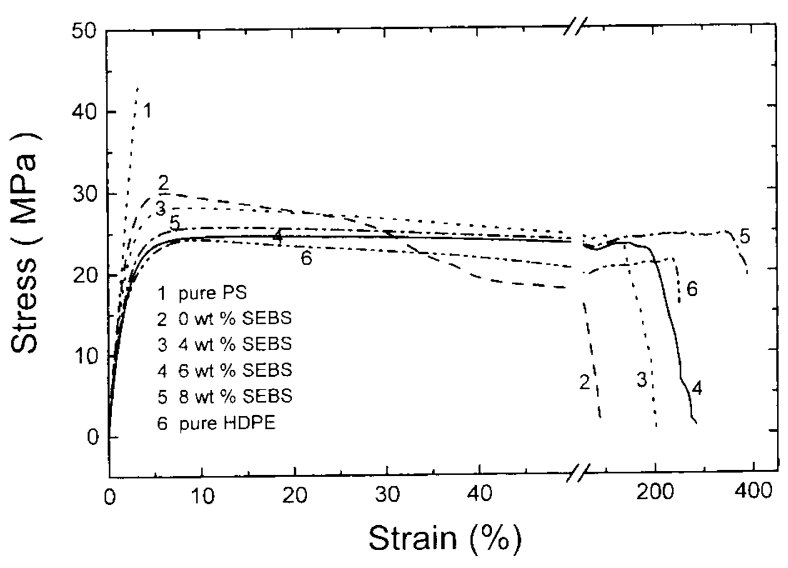

Figure 2. Stress-strain curves of PS, HDPE, and their compatibilized HDPE/PS 80/20 blends.

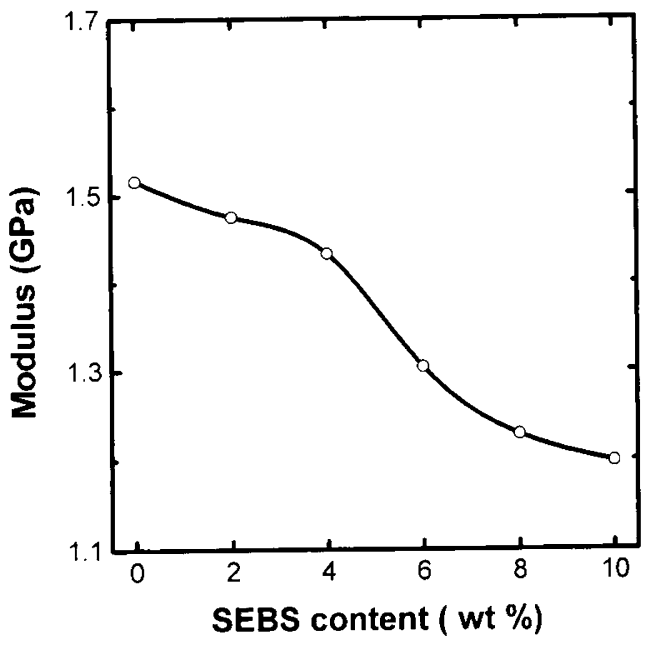

Figure 3. Plot of modulus of the blends versus SEBS content.

parent components. ${ }^{15}$ In the present study, the HDPE/ PS 80/20 blend compatibilized by the tri-block SEBS copolymer exhibits an obvious improvement in the tensile ductility. The result convincingly demonstrates that the tri-block SEBS copolymer strengthens the interfacial adhesion between HDPE and PS, acting as the role of a compatibilizer agent. Though SEBS addition is beneficial in improving the tensile ductility of HDPE/PS blend, but it degrades the tensile stiffness and yield strength of the blend specimens, particularly when the SEBS content $\geq 6 \mathrm{wt} \%$. As mentioned above, the morphology of HDPE/PS $80 / 20$ blend specimens show little change when the SEBS content exceeds $6 \mathrm{wt} \%$. In view of the morphology and interfacial adhesion effects consideration, there is a critical concentration for SEBS in HDPE/ PS $80 / 20$ blend, i. e., $6 \mathrm{wt} \%$. In this regard, the SEBS content of HDPE/PS blend should be limited up to $6 \mathrm{wt} \%$. Fayt et al. ${ }^{14}$ indicated that SEBS tends to selectively disperse in HDPE phase when SEBS content $\geq 6 \mathrm{wt} \%$ on the basis of transmission electron microscopic observation.

We now consider the effect of SEBS content on the fracture toughness of the HDPE/PS 80/20 specimens. The fracture toughness is determined by means of the essential work method. According to this method, the total work of fracture $\left(W_{\mathrm{f}}\right)$ of a sample having a sharp crack can be divided into two parts, i.e., the essential

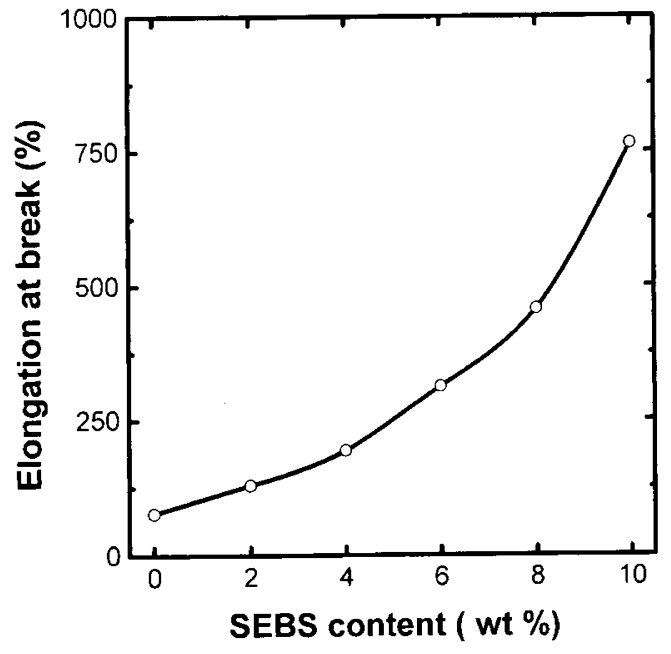

Figure 4. Plot of elongation at break of the blends versus SEBS content.

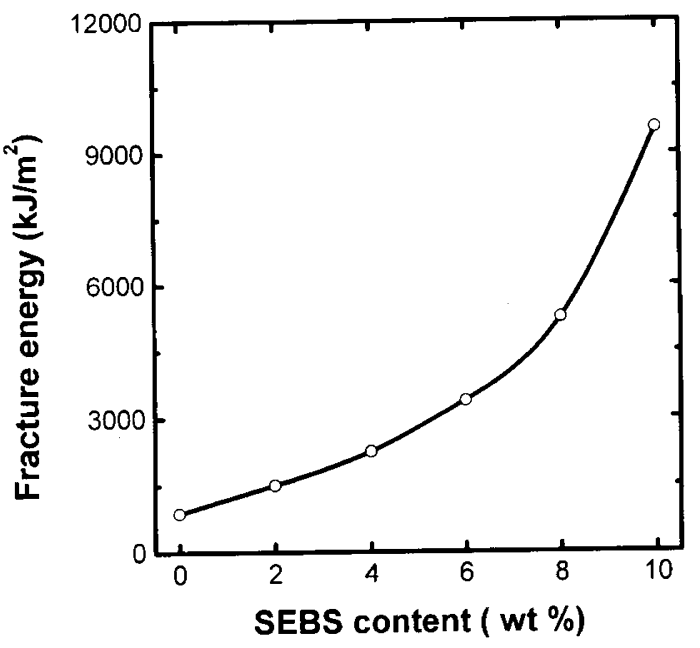

Figure 5. Plot of break energy of the blends versus SEBS content.

work of fracture $\left(W_{\mathrm{e}}\right)$ required to fracture the polymer in its process zone, and non-essential or plastic work $\left(W_{p}\right)$ consumed by various deformation mechanisms in the plastic zone. ${ }^{27}$ Mathematically, $W_{\mathrm{f}}$ can be expressed as follows,

$$
W_{\mathrm{f}}=W_{\mathrm{e}}+W_{\mathrm{p}}
$$

Taking into consideration that $W_{\mathrm{e}}$ is surface-related, whereas $W_{\mathrm{p}}$ is volume-related, $W_{\mathrm{f}}$ can be given by the related specific work terms (i.e., $w_{\mathrm{e}}$ and $w_{\mathrm{p}}$, respectively), ${ }^{29}$

$$
\begin{aligned}
& W_{\mathrm{f}}=w_{\mathrm{e}} L t+\beta w_{\mathrm{p}} L^{2} t \\
& w_{\mathrm{f}}=\frac{W_{\mathrm{f}}}{L t}=w_{\mathrm{e}}+\beta w_{\mathrm{p}} L
\end{aligned}
$$

where $L$ is the ligament length, $t$ is the thickness of the specimen and $\beta$ is a shape factor related to the form of the plastic zone. Based on the eq 3 , the specific essential work can be determined from the intercept of the linear plot of $w_{\mathrm{f}}$ versus $L$. However, the explicit determination of $w_{\mathrm{p}}$ is very difficult owing to a lacking in the knowledge of the shape factor $\beta$.

Figure 7 shows the typical load-displacement $(\mathrm{P}-\delta)$ 


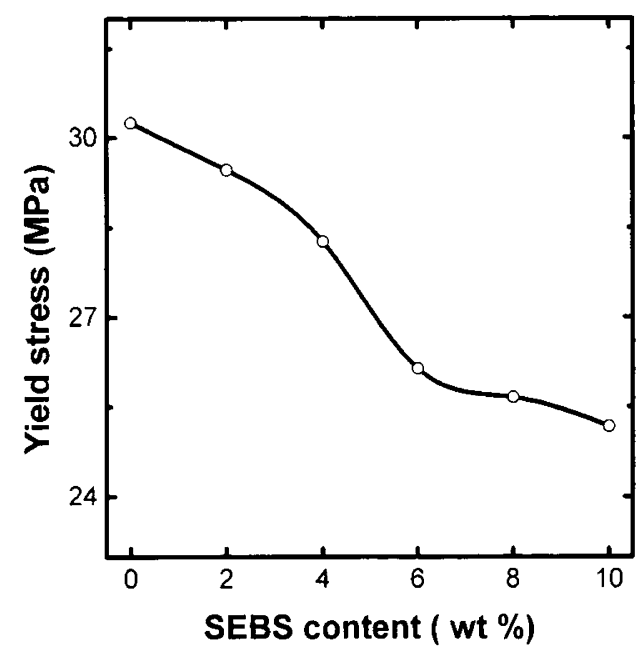

Figure 6. Plot of yield stress of the blends versus SEBS content.

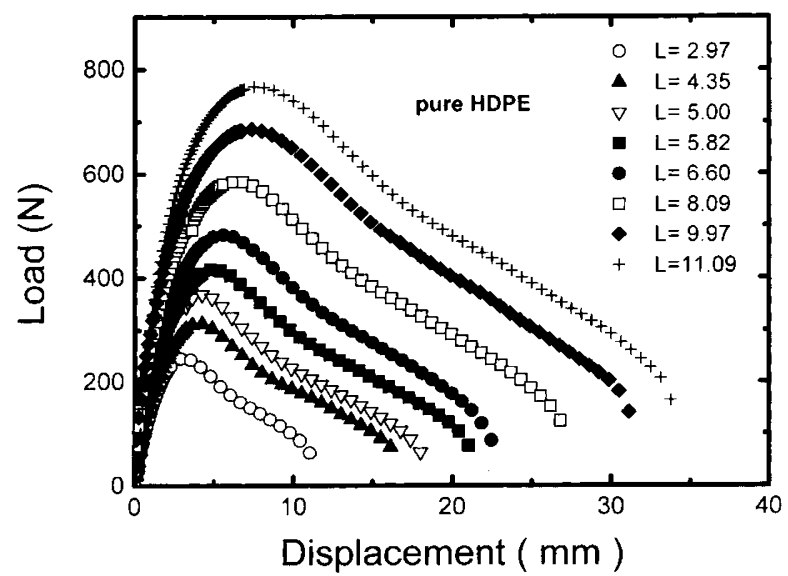

Figure 7. Load-displacement diagrams for SENT specimens of pure HDPE at various ligament lengths tested at a crosshead displacement rate of $1 \mathrm{~mm} \mathrm{~min}^{-1}$ (sample width $=25 \mathrm{~mm}$, gauge length $=100 \mathrm{~mm}$ ).

curves of HDPE homopolymer at various ligament lengths. It is apparent that HDPE fractures in a ductile manner under the testing conditions employed. All specimens exhibit gross yielding and necking during the tensile deformation process. A similarity in the shape of these curves indicates that the fracture mode is independent of ligament length. ${ }^{30}$ The load-displacement curves of HDPE/PS 80/20 compatibilized by $10 \mathrm{wt} \%$ of SEBS is shown in Figure 8.

It is considered that the razor-notched cracks of SEN specimens open-up during the initial loading. Further increases in load leads to crack blunting and the development of a necked down plastic zone ahead of the crack tip. The maximum load in the $\mathrm{P}-\delta$ diagrams of Figure 7 signifies the load at which sufficient yielding in the ligament area had taken place. Further propagation of the crack leads to a progressive decrease in load until final rupture of the specimens. The presence of a sharp notch has a dramatic effect on the shape $\mathrm{P}-\delta$ diagrams during tensile loading. Ductile polymer, e.g., PP, containing a sharp notch, experiences a fully brittle behavior because it shows no sign of plasticity in the $\mathrm{P}-\delta$ diagram. ${ }^{31}$ From Figure 7, HDPE shows ductile behavior due to it exhibits

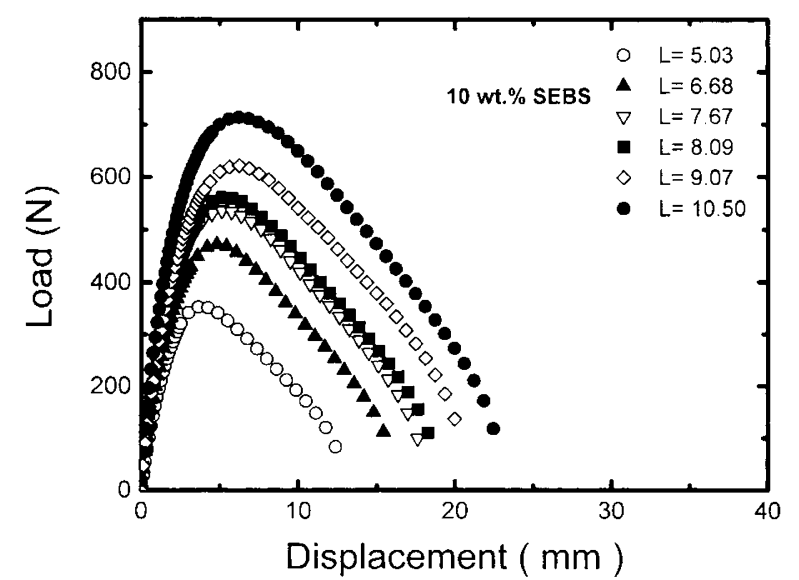

Figure 8. Load-displacement diagrams for SENT specimens of HDPE/PS $80 / 20$ blend containing $10 \mathrm{wt} \%$ SEBS at various ligament lengths tested at a crosshead displacement rate of $1 \mathrm{~mm}$ $\mathrm{min}^{-1}$ (sample width $=25 \mathrm{~mm}$, gauge length $=100 \mathrm{~mm}$.

a maximum load associated with the yielding of ligament area, and to the presence of an extensive displacement after peak loading. The latter case is more pronounced for HDPE specimens with a larger ligament length. In other words, HDPE experiences a ductile failure with slow stable crack growth. Though compatibilized HDPE/PS blends also exhibits a maximum load, but the displacement after peak loading is considerably reduced when compared to HDPE with the same ligament length of $8.09 \mathrm{~mm}$ (Figure 8). According to eq $2, \beta$ $w_{\mathrm{p}}$ represents the extent of plastic deformation that the material has undergone during the fracture process, and it is determined by the nature of material. Moreover, the energy dissipated in the plastic zone for polymers involves microvoiding and shear yielding. Huang and Norman reported that crazes tend to form in the plastic zone of an advanced crack during tensile loading of the razornotched HDPE specimens. ${ }^{32}$ In the case of SEBS compatibilized HDPE/PS blends, it is considered that a considerable plastic deformation is dissipated in the plastic zone of an advanced crack for the debonding of PS fibrils from the HDPE matrix. This is because SEBS improves the interfacial adhesion between the PS fibrils and HDPE matrix considerably.

From the areas under the load-displacement diagrams, the specific work of fracture, $w_{\mathrm{f}}$ is determined. The plots of $w_{\mathrm{f}}$ versus ligament $(L)$ for HDPE and the compatibilized blends are shown in Figures 9-12. It is evident from these figures that a linear relationship exists between $w_{\mathrm{f}}$ and $L$. A linear regression method is used to analyze the linear portion of the data in Figures $9-12$, and the results are summarized in Table $\mathrm{I}$.

As can be seen, the essential work $\left(w_{\mathrm{e}}\right)$ of pure HDPE is about $83.4 \mathrm{~kJ} \mathrm{~m}^{-2}$, and it is remarkably higher than that of compatibilized blends. Furthermore, $w_{\mathrm{e}}$ of the compatibilized HDPE/PS 80/20 blends increases with increment of SEBS content. However, the non-essential work $\left(\beta w_{\mathrm{p}}\right)$ of the compatibilized blends shows little variation with SEBS content. Besides, it is found that the non-essential work of the compatibilized HDPE/PS blends is much lower than that of pure HDPE.

According to our previous TEM observations for the PS/HDPE/SEBS system, ${ }^{21}$ fracture cracks always initi- 


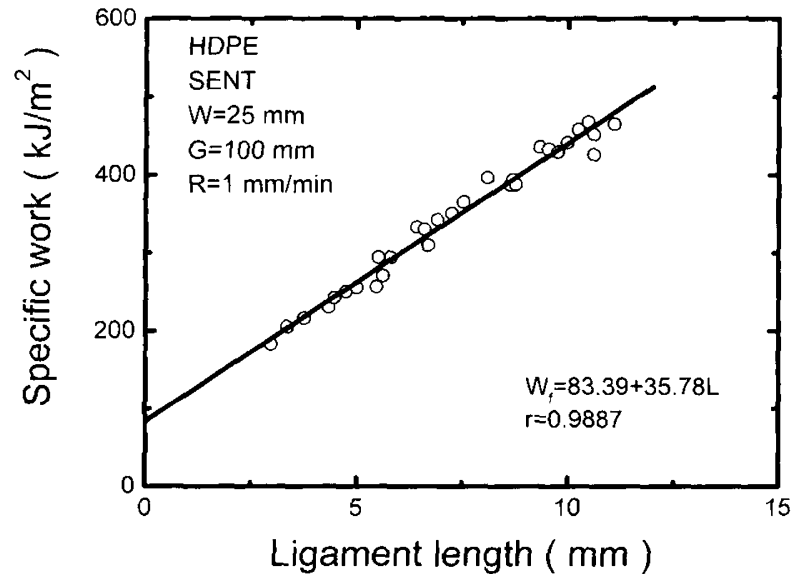

Figure 9. Total specific work of fracture $\left(w_{\mathrm{f}}\right) v s$. ligament length $(L)$ for HDPE determined at a crosshead displacement rate of 10 $\mathrm{mm} \mathrm{min}{ }^{-1}$ (sample width $=25 \mathrm{~mm}$, gauge length $=100 \mathrm{~mm}$ ).

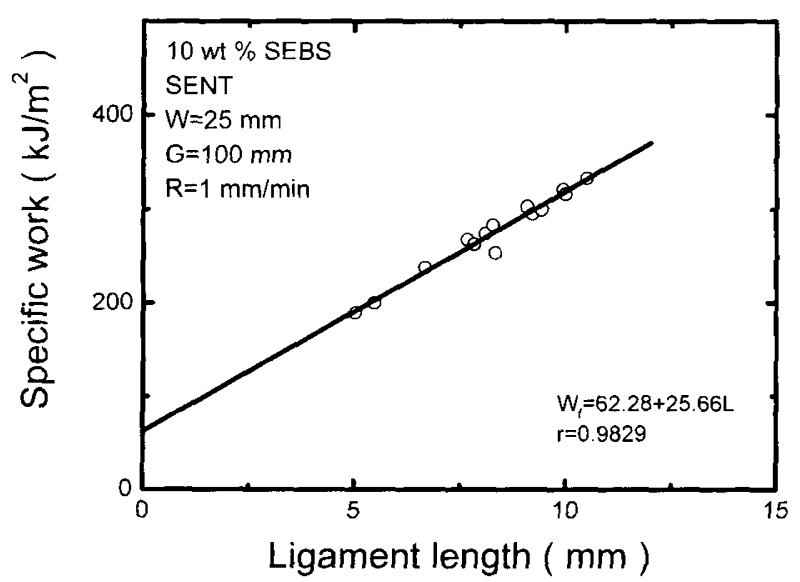

Figure 10. Total specific work of fracture $\left(w_{\mathrm{f}}\right)$ us. ligament length $(L)$ for HDPE/PS 80/20 blend containing $10 \mathrm{wt} \%$ SEBS determined at a crosshead displacement rate of $10 \mathrm{~mm} \mathrm{~min}^{-1}$ (sample width $=25 \mathrm{~mm}$, gauge length $=100 \mathrm{~mm}$ ).

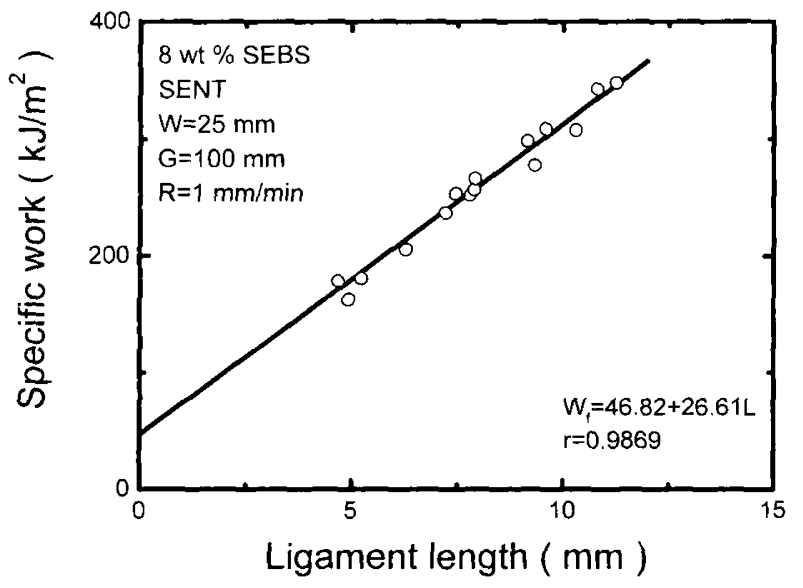

Figure 11. Total specific work of fracture $\left(w_{\mathrm{f}}\right)$ vs. ligament length $(L)$ for HDPE/PS $80 / 20$ blend containing 8 wt $\%$ SEBS determined at a crosshead displacement rate of $10 \mathrm{~mm} \mathrm{~min}^{-1}$ (sample width $=25 \mathrm{~mm}$, gauge length $=100 \mathrm{~mm}$ ).

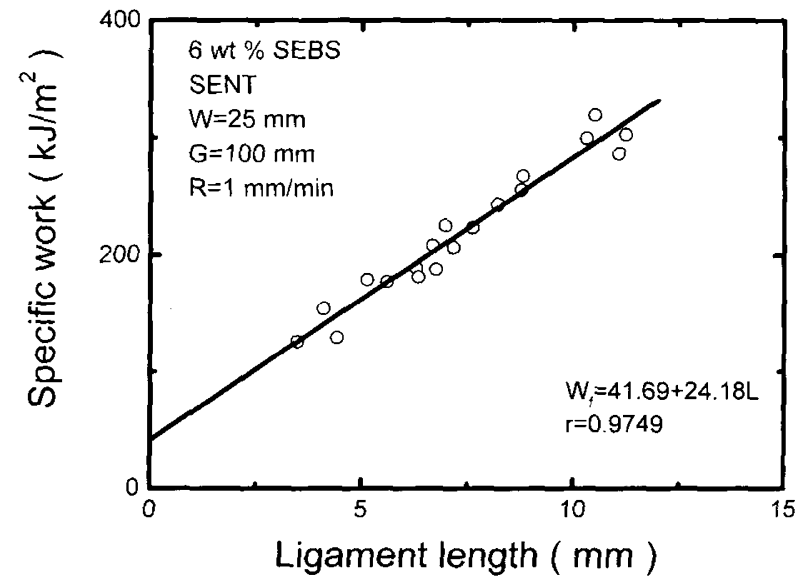

Figure 12. Total specific work of fracture $\left(w_{\mathrm{f}}\right)$ vs. ligament length $(L)$ for HDPE/PS $80 / 20$ blend containing 6 wt $\%$ SEBS determined at a crosshead displacement rate of $10 \mathrm{~mm} \mathrm{~min}^{-1}$ (sample width $=25 \mathrm{~mm}$, gauge length $=100 \mathrm{~mm}$ ).

Table I. Work of fracture of pure HDPE and HDPE/PS 80/20 blends compatibilized by different amounts of SEBS

\begin{tabular}{ccccc}
\hline $\begin{array}{c}\text { Content of SEBS } \\
\text { wt\% }\end{array}$ & Regression equation & $\frac{\text { Essential work }}{W_{\mathrm{e}} / \mathrm{kJ} \mathrm{m}^{-2}}$ & $\frac{\text { Non-essential work }}{\beta W_{\mathrm{p}} / \mathrm{kJ} \mathrm{m}^{2}}$ & \multicolumn{2}{c}{ Correlation efficient } \\
\hline 10 & $W_{\mathrm{f}}=62.28+25.66 \mathrm{~L}$ & 62.28 & 25.66 & 0.9829 \\
8 & $W_{\mathrm{f}}=46.82+26.61 \mathrm{~L}$ & 46.82 & 26.60 & 0.9869 \\
6 & $W_{\mathrm{f}}=41.69+24.18 \mathrm{~L}$ & 41.69 & 24.18 & 0.9749 \\
Pure HDPE & $W_{\mathrm{f}}=83.39+35.78 \mathrm{~L}$ & 83.39 & 35.78 & 0.9887 \\
\hline
\end{tabular}

ate at the interfaces of PS and HDPE phases during the tensile process. In this context, pure HDPE having a single phase possesses a higher essential work than the compatibilized HDPE/PS blends. Moreover, the interfacial adhesion is obviously enhanced with increasing the compatibilizer content, thus the essential work of the HDPE/PS 80/20 blend specimens increases with the increment of SEBS, owing to a higher energy is needed to fracture a strong interface than a poor one.

It is worth-noting that we only determine the fracture toughness of compatibilized HDPE/PS blends containing SEBS content $\geq 6 \mathrm{wt} \%$. For the HDPE/PS blends containing SEBS content $<6$ wt\%, the SENT samples fracture in a brittle manner, and no necking and contraction occur during the tensile process. In this case, the loaded samples are not under the state of a plane stress. It is well known that the essential work is just applicable for ductile materials under the plane stress, therefore the fracture toughness of the compatibilization HDPE/PS blends containing SEBS less than $6 \mathrm{wt} \%$ cannot be evaluated by the essential work concept.

\section{CONCLUSIONS}

From the above results, the following conclusions can be drawn :

1. The HDPE/PS 80/20 blend without SEBS exhibits a low tensile ductility owing to a weak interfacial adhesion 
between HDPE and PS phases. The ductility of HDPE/ PS blends can be improved dramatically by the addition of SEBS. But the stiffness and yield stress of HDPE/PS blends appear to decrease with increasing SEBS content.

2. SEM observation reveals that the HDPE/PS 80/20 samples containing different amounts of SEBS show a two-phase structure. The PS phase is dispersed in the HDPE matrix as long fibers. The diameter of PS fibers in the uncompatibilized blends is considerably larger than that of the compatibilized blends.

3. The specific work $\left(w_{\mathrm{e}}\right)$ and non essential work term $\left(\beta w_{\mathrm{p}}\right)$ of HDPE are greatly higher than those of the HDPE/PS 80/20 blends, indicating that the crack resistance of HDPE is decreased after blending with PS.

4. The essential work of the compatibilized HDPE/PS $80 / 20$ blends tends to increase with the increment of SEBS content, but the non-essential work of the compatibilized blends shows little variation with SEBS content.

Acknowledgments. S. A. Xu would like to thank Croucher Foundation for providing a fellowship to visit City University of Hong Kong.

\section{REFERENCES}

1. C. R. Lindsey, D. R. Paul, and J. W. Barlow, J. Appl. Polym. Sci., 26, 1(1981).

2. M. A. Rames and E. P. Collar, J. Polym. Eng., 7, 137(1987).

3. J. W. Teh and A. Rudin, Polym. Eng. Sci., 31, 1033(1991).

4. R. C. Willemse, A. Pothuma de Boer, J. van Dam, and A. D. Gotsis, Polymer, 39, 5879(1998).

5. Y. J. Sun, Richard J. G. Willemse, T. M. Liu, and Warren E. Baker, Polymer, 39, 2201(1998).

6. W. E. Baker and M. Saleem, Polymer, 28, 2057(1987).

7. Z. Wang, C. M. Chan, S. H. Zhu, and J. R. Shen, Polymer, 39, 6801(1998).
8. H. E. Hermes and J. S. Higgins, Polym. Eng. Sci., 38, 847 (1998).

9. I. Luzinov, K. Xi, C. Pagnoulle, G. Huyanh-Ba, and R. Jerome, Polymer, 40, 2511(1999).

10. H. E. Hermes, D. G. Bucknall, J. S. Higgins, and R. L. Scherrenberg, Polymer, 39, 3099(1998).

11. S. C. Tjong and S. A. Xu, J. Appl. Polym. Sci., 68, 1099 (1998).

12. W. M. Barentsen and D. Heikens, Polymer, 14, 579(1973).

13. C. E. Loke and D. R. Paul, J. Appl. Polym. Sci., 13, 308 (1983).

14. R. Fayt, R. Jerome, and Ph. Teyssie, J. Polym. Sci., Polym. Lett. Ed., 24, 25(1986)

15. R. Fayt, R. Jerome, and Ph. Teyssie, J. Polym. Sci., Polym. Phys. Ed., 20, 2209(1982).

16. R. Fayt, R. Jerome, and Ph. Teyssie, J. Polym. Sci., Polym. Phys. Ed., 33, 801(1995).

17. M. C. Schwarz, H. Keskkula, J. W. Barlow, and D. R. Paul, J. Appl. Polym. Sci., 35, 653(1988).

18. M. Saleem and W. E. Baker, J. Appl. Polym. Sci., 39, 655 (1990).

19. H. Feng, J. Tian, and C. Ye, J. Appl. Polym. Sci., 61, 2265 (1996).

20. T. Li, V. A. Topolkaraev, A. Hiltner, E. Baer, X. Z. Ji, and P. Quirk, J. Polym. Sci., Polym. Phys. Ed., 33, 667(1995).

21. S. A. Xu, M. Jiang, and J. S. Shen, Polym. J, 27, 607(1995).

22. S. A. Xu, and C. M. Chan, Polym. J., 30, 552(1998).

23. M. Taha and V. Frerejean, J. Appl. Polym. Sci., 61, 969 (1996).

24. N. Mekhilef, B. D. Favis, and P. J. Carreau, J. Polym. Sci., Polym. Phys. Ed., 35, 293(1997).

25. M. N. Bureau, H. E. Kadi, J. Denault, and J. I. Dickson, Polym. Eng. Sci., 37, 377(1997).

26. M. C. Scharwarz, J. W. Barlow, and D. R. Paul, J. Appl. Polym. Sci., 35, 2053(1988).

27. K. B. Broberg, Int. J. Fract. Mech., 4, 11 (1968).

28. S. Hashemi, Polym. Eng. Sci., 37, 912 (1997).

29. J. K. Kocsis and T. Czigany, Polymer, 37, 2433(1996).

30. J. K. Kocsis and T. Czigany, Polymer, 38, 4587(1996).

31. D. E. Mouzakis, F. Stricker, R. Mulhaupt, and J. K. Kocsis, J. Mater. Sci., 33, 2551 (1998).

32. Y. L. Huang and N. Brown, Polymer, 33, 2989 (1992). 